\title{
Cancer Risk Due to the Natural Radioactivity in Cigarette Tobacco
}

\author{
Ali A. Ridha1, Hasan A. Hasan² \\ ${ }^{1}$ Department of Physics, College of Science, Al-Mustansiriyah University, Baghdad, Iraq \\ ${ }^{2}$ Ibn Sina University of Medical and Pharmaceutical Sciences, Baghdad, Iraq \\ Email: dr.aliabdulwahab@yahoo.com,hasn0010@yahoo.com
}

Received 26 April 2016; accepted 10 June 2016; published 13 June 2016

Copyright (C) 2016 by authors and Scientific Research Publishing Inc.

This work is licensed under the Creative Commons Attribution International License (CC BY). http://creativecommons.org/licenses/by/4.0/

(c) (i) Open Access

\begin{abstract}
Thirty-one samples of cigarettes have been collected from local markets of different types of origins. The samples were selected according to a survey distributed to smokers by paper and digital survey to see the most heavily traded among smokers and in addition to a number of questions to see how the awareness and the culture of smokers in diseases caused by smoking and considered this study the first survey in Iraq. The aim of this research is to assess the number of cancer cases due to cigarette smoking. Through the use of High-Purity Germanium system (HPGe) (efficiency $40 \%)$ we determinated the radionuclides in cigarette tobacco. The average values were $(14.86 \pm$ $3.76,10.84 \pm 3.13,1050.64 \pm 47.57) \mathrm{Bq} / \mathrm{kg}$ for $\mathrm{Ra}-226$, Th-232 and $\mathrm{K}-40$, respectively, and the excess lifetime of cancer risk values ranged from 0.54 to 130 at average of 76 per million person per year. $R a_{e q}$ values varied from 18.50 to $87.21 .4 \mathrm{~Bq} / \mathrm{kg}$ with an average value of $39.51 \mathrm{~Bq} / \mathrm{kg}$ for tobacco samples. The annual effective dose $\left(H_{E}\right)$ varies from $16.38 \mu \mathrm{Sv} / \mathrm{y}$ to $44.69 \mu \mathrm{Sv} / \mathrm{y}$ with an average value of $24.97 \mu \mathrm{sv} / \mathrm{y}$. The Annual Gonadal Dose Equivalent (AGDE) varies from 0.3 to 0.64 $(\mathrm{mSv} / \mathrm{y})$ with an average value of 0.42 for all tobacco samples under investigation.
\end{abstract}

\section{Keywords}

NORM, Tobacco, Annual Effective Dose, Excess Cancer Risk, HPGe, AGDA

\section{Introduction}

The link between cigarette smoke and cancer has long been established. Smokers are 10 times at a greater risk of developing lung cancer than that of non-smokers [1]. Radioactive nuclides of the uranium-radium series, such as Pb-210 and Po-210, have long been associated with tobacco plants [2]. Tso, Harley and Alexander (1966) stated that the principal mechanism of incorporation involves uptake into roots from the soil and phosphate fertilizers. The properties and distribution of trichomes (hairs) on tobacco leaf surfaces suggest that they are effective col- 
lectors of small Aitken (nuclei) particles (50.1 mm diameter) by means of diffusive deposition due to Brownian motion of the particles [3] [4]. As about $85 \%$ of tobacco trichomes have glandular heads coated with a sticky exudate mixture of organic compounds, trichomes may retain the small atmospheric particles which are deposited on the glandular heads throughout the period of plant growth [5] [6]. This study is important because the research concerned with human beings in general and in particular the health of smokers, so it must assess the radiological hazards of radioactive nuclides in the smoke of cigarettes and tobacco through the following objectives:

1) To estimate the levels of natural radionuclides concentrations in tobacco and cigarette smoke.

2) To check if the radioactivity in tobacco may be or not the main reason of increasing the lung cancer in smokers especially in Iraq.

3) To pay attention to human health through the warning from some types of cigarettes that contains high level of radionuclides concentrations.

\section{Theoretical Considerations}

\subsection{The Specific Activity of Radionuclides}

The specific activity $A_{i}\left(E_{\gamma}\right)$ of radionuclide $i$ measured in $\mathrm{Bq} / \mathrm{kg}$, for a peak at energy $E_{\gamma}$, is given by [7]:

$$
A_{i}\left(E_{\gamma}\right)=\frac{N}{t \times I_{\gamma}\left(E_{\gamma}\right) \times \varepsilon\left(E_{\gamma}\right) \times m}
$$

where $N$ is the net peak area under the specific peak corrected for the background at energy $E_{\gamma}, t$ is the time of measurement in second, $I_{\gamma}\left(E_{\gamma}\right)$ is the abundance at energy $E_{\gamma}, \varepsilon\left(E_{\gamma}\right)$ is the detection efficiency at energy $E_{\gamma}$ and $m$ is the weight of the measured sample in $\mathrm{kg}$.

\subsection{Annual Effective Dose}

Assuming ( $0.82 \pm 0.1 \mathrm{~g}$ ) of tobacco per cigarette and a smoker was smoking 30 cigarettes (one and a half packs) per day or $24.6 \mathrm{~g}$ of tobacco per day, then the annual consumption of tobacco by cigarettes is estimated to be $8.979 \mathrm{~kg} / \mathrm{y}$. Taking into consideration the data for the radionuclide concentrations $(\mathrm{Bq} / \mathrm{kg})$ in tobacco fresh, the fraction of the radionuclide activity concentration that is recovered from cigarette tobacco to cigarette smoke is 0.75 (75\%), as on the average, about $75 \%$ of the radioisotope in the cigarette tobacco was contained in the cigarette smoke, which is partially inhaled and deposited in the lung tissues and about $25 \%$ was retained in the cigarette filter and ash [8]. The most recent dose conversion coefficients of the radionuclides (Sv/Bq) for the case of inhalation for adults (smokers) is presented in Table 1, then measurements are derived for the annual effective dose, $H_{E}(\mathrm{~Sv} / \mathrm{y})$, due to inhalation for adults (smokers), according to the equation (2) [9]:

$$
H_{E}=0.75 \times M_{T} \times A_{i} \times F
$$

where $M_{T}(\mathrm{~kg} / \mathrm{y})$ refers to the annual amount (in mass) of tobacco consumed, $A_{i}(\mathrm{~Bq} / \mathrm{kg})$ refers to the specific activity of the ith radionuclide and $F(\mathrm{~Sv} / \mathrm{Bq})$ refers to the dose conversion factor as written in Table 1 [10] [11].

\subsection{Annual Gonadal Dose Equivalent (AGDE)}

The gonads, the activity bone marrow and the bone surface cells are considered as organs of interest by (UNSCEAR, 1988) because the most sensitive parts of the human body to radiation. An increase in AGED has been known to affect the bone marrow, causing destruction of the red blood cells that are then replaced by white blood cells. This situation results in a blood cancer called leukemia which is fatal, The annual gonadal dose equivalent (AGDE) in mSv/y due to the activity concentrations of Ra-226, Th-232, and K-40 was calculated using the following formula [13] [14]:

$$
\operatorname{AGDE}(\mathrm{mSv} / \mathrm{y})=\left(3.09 A_{R a}+4.19 A_{T h}+0.314 A_{K}\right) / 1000
$$

\subsection{Radium Equivalent Activity}

To represent the activity concentrations of Ra-226, Th-232 and K-40 by a single quantity, which takes into account the radiation hazards associated with them, a common radiological index has been introduced. The index 
Table 1. Effective dose conversion factors for inhalation for adults [12].

\begin{tabular}{cc}
\hline Radionuclide & Sv/Bq \\
\hline Pb-214 & $4.8 \times 10^{-9}$ \\
$\mathrm{~Pb}-212$ & $3.3 \times 10^{-8}$ \\
$\mathrm{Bi}-214$ & $1.2 \times 10^{-8}$ \\
$\mathrm{Ac}-228$ & $2.9 \times 10^{-8}$ \\
$\mathrm{~K}-40$ & $3.0 \times 10^{-9}$ \\
\hline
\end{tabular}

called Radium equivalent activity $\left(R a_{e q}\right)$ is used to ensure the uniformity of the distribution of natural radionuclides Ra-226, Th-232 and K-40 and is given by the expression [15]:

$$
R a_{e q}=A_{R a}+1.43 A_{T h}+0.077 A_{K}
$$

where, $A_{R a}, A_{T h}$ and $A_{K}$ are the specific activities concentrations (Bq/kg) of Ra-226 (U-238 series), Th-232 and $\mathrm{K}-40$, respectively. It was assumed that $370 \mathrm{~Bq} / \mathrm{kg}$ of Ra-226, $259 \mathrm{~Bq} / \mathrm{kg}$ of Th-232 and $4810 \mathrm{~Bq} / \mathrm{kg}$ of K-40 produce the same gamma-ray dose rate. The maximum dose $R a_{e q}$ must be less than $370 \mathrm{~Bq} / \mathrm{kg}$ for safe use, i.e., to keep the external dose below $1.5 \mathrm{mSv} / \mathrm{y}$.

\subsection{Excess Lifetime Cancer Risk (ELCR)}

This gives the probability of developing cancer over a lifetime at a given exposure level, It is presented as a value representing the number of extra cancers expected in a given number of people with exposure to a carcinogen at a given dose, and we can calculate (ELCR) by equation (5) if considering 70 years as the average duration of life for human being [13].

$$
E L C R=\left(\Sigma H_{E}\right) \times D_{L} \times R_{F}
$$

where, $\Sigma H_{E}$ is the, the sum of Annual Effective Dose for (U-238, Th-232, K-40) DL is the average Duration of Life (estimated to be 70 years) and RF is the risk factor $\left(\mathrm{Sv}^{-1}\right)$, fatal cancer risk per Sievert. For low dose background radiations which are considered to produce stochastic effects, ICRP uses values of 0.05 for the public exposure [16]. This value-free units because it represents the probability of cancer incidence through this we can deduce the equation above.

\section{Materials and Methods}

Thirty one sample of different kinds of tobacco cigarettes were collected from Iraqi Market by 10 packets (200 cigarettes) each type. It is chosen in terms of the most common type used by smokers. The collected samples were grind to a fine powder after removing the paper and filters from cigarettes, using hand mill and electrical China mill. The fine powder will convert to the grain size of $650 \mu \mathrm{m}$ using special Germany sieves (mesh). The samples were packaged in a 1 liter Marinelli beaker, the sealed marinelli beaker were kept for eight weeks before measurements in order to achieve the secular equilibrium for U-238 and Th-232 with their respective progenies. The net weight of the samples has been measured. Gamma rays, due to the environmental radioactivity emitters, in the cigarettes tobacco samples were subjected to gamma spectrometry system, which consist of coaxial (HPGe) detector, with an efficiency of $40 \%$ as shown in Figure 1.

The procedure of the detector is to produce a signal for the incident gamma-ray on the detector generates a linear charge pulse. The primary purpose of the preamplifier is to provide an optimized coupling between the output of the detector and the rest of the counting system. The preamplifier is also necessary to minimize any sources of noise that may change the signal. The preamplifier shapes the signal and reduces its attenuation.

A standard mix source (Marnilli beaker) was used, in order to calibrate the efficiency of the detector. An accurate efficiency of the system is necessary to quantify the present radionuclide in the samples. It is essentialy that all system setting and adjustment have been repeated many times in order to determine the efficiency calibration and dependent finaly for measureing of our samples. A slightly changes in the settings of the system components may be give a direct effects on the efficiency measurement. To draw the calibration curve using the 


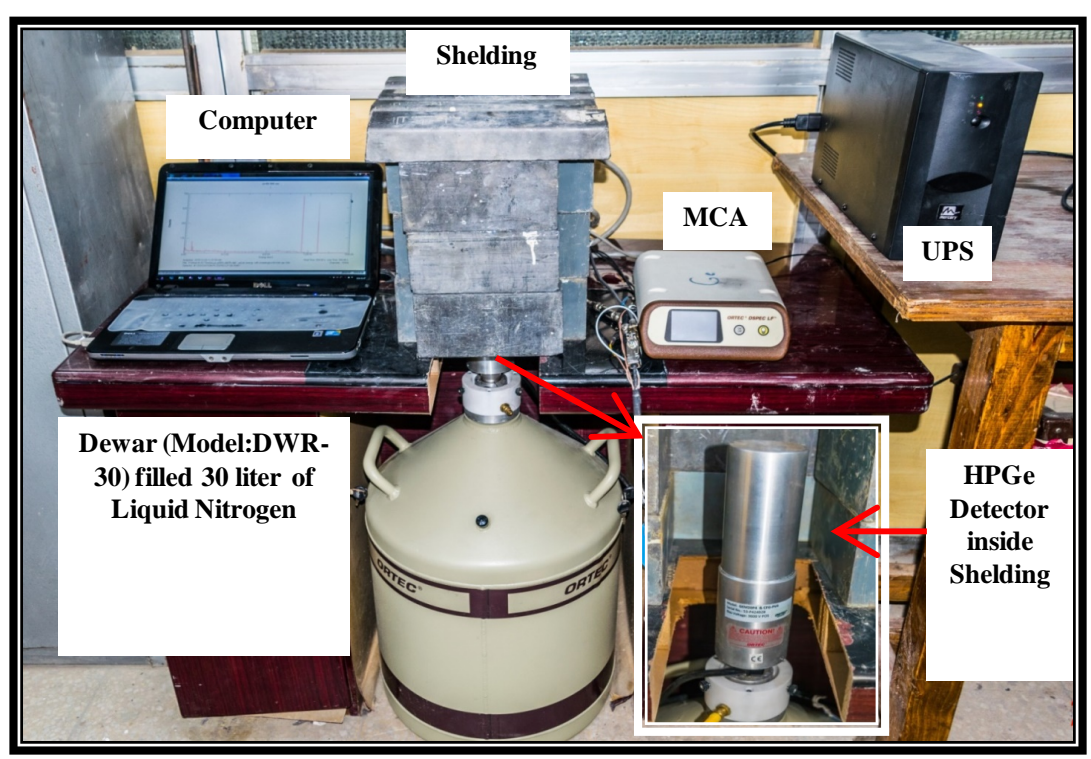

Figure 1. Represent all parts of HPGe system.

energies (59.5, 88, 166, 122, 1173.24, 1332.5, 661.66, 392, 898) keV by the following equation [17]:

$$
\varepsilon\left(E_{\gamma}\right)=\frac{\text { Net }}{A \times I_{\gamma}\left(E_{\gamma}\right) \times t} \times 100 \%
$$

where: $\varepsilon\left(E_{\gamma}\right)$ : is the detection efficiency at energy $E_{\gamma}$. Net: is the net peak area under the specific peak corrected for the background at energy $E_{\gamma}$. A: is the activity in $(\mathrm{Bq})$ After correction evry isotope in the standard mix source at the measuring date (22/12/2015) using equation $\left(A=A_{o} \mathrm{e}^{-\lambda t}\right) \cdot I_{\gamma}\left(E_{\gamma}\right)$ is the abundance at energy $E_{\gamma} . t$ is the time of measurement $(86,400 \mathrm{sec})$.

The efficiency calibration curve for (HPGe) detector system by measuring the standard mix source as shown in Figure 5.

\section{Results and Discussion}

Specific activity of the samples adopted on the Lead isotope (Pb-214) at energies (295.21 and 351.92) keV and Bismuth (Bi-214) at energy (609.32 keV) the specific activity adopted on the Lead isotope (Pb-212), Thallium (Tl-208) and Actinium are equivalent to the specific activity of Uranium (U-238) by choosing the avearge value of their activities, While (Ac-228) at energies (238.63, 583.19 and 911.16) keV respectively, are equivalent to the specific activity of Thorium (Th-232) by choosing the avearge value of their activities. The specific activity of radionuclides K-40 have been calculated by using their energies (1460.80) keV.

\subsection{Survey Information from the Smokers}

The aims of our survey are to know which types of cigarettes widely used by the smokers, in addition to the important information like diseases associated with smoking, including lung cancer, heart or other diseases. The survey included a more than one hundred of smokers from Iraq and 100 from different countries, the survey Procedure as shwon digram:

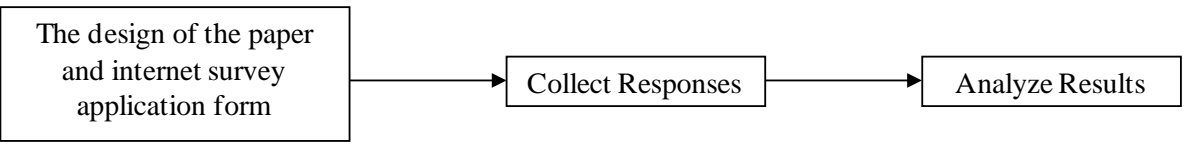

\subsubsection{Paper Survey}

Paper survey was including the distribution of more than 100 sheets of paper (contain the a questions) to Iraqi 
smokers with different age and sex, some of are students, lecturers and the others are some persons from the street, this survey was completed during in 2014, The results of the survey All smokers who have undergone these questions are from Iraq, Asked smokers do you know that tobacco cigarettes contain radionuclides which are deposited on the inner membrane of the lung? the answer is $69 \%$ (Yes) and 31\% (No), as shown Figure 2, $84 \%$ Percentage of smokers who smoke a cigarette to the end while $16 \%$ do not smoke it to the end, This is dangerous indication that $84 \%$ of smokers lungs are exposed to a radiation dose larger than smokers who do not complete their cigarettes to the end as shown Figure 3, the Percentage of average number of cigarettes was smoking per day, $45 \%$ from smokers was smoking 20 cigarette per day, $24 \%$ for 40 cigarette per day, $18 \%$ for 10 cigarette per day, 13\% for 30 cigarette per day as shown Figure 4.

\subsubsection{Internet Survey}

In order to get a more information to expanded our results for the smokers from other countries. internet survey has been done by a special application using the same questions in the previous paragraph through the website known work Surveys.

This site construction an application form such as link which can be published on social media or send it via email, the survey link has been published in the social media sites (Facebook, Twitter, Instagram and Viber) in order to be answered by all smokers who are in any country around the world, we obtained the answer of questions by 100 smoker from different countries. This survey was completed during July and August in 2015

The results of the survey $79 \%$ of smokers in this survey from Iraq, 6\% from Egypt, 5\% from Syria, 3\% from Tunisia, 1\% from Oman, 1\% from Bahrain, 1\% from KSA, 1\% from France, 1\% from Spain as shown Figure 5. Asked smokers do you know that tobacco cigarettes contain radionuclides which are deposited on the inner membrane of the lung? The answer was 56\% (Yes) and $44 \%$ (No), as shown Figure 6. the Percentage of average number of cigarettes was smoking per day is $50 \%$ for smokers was smoking 20 cigarette per day, $20 \%$ for 40 cigarette per day, 22\% for 10 cigarette per day, 8\% for 5 cigarette per day as shown in Figure 7.

\subsection{The Specific Activity of Radionuclides}

Table 2 tabulated the results of the specific activity calculations of U-238, Th-232, K-40, radionuclides for 31 samples of tobacco from different countries which are widely used in Iraq. It is clear from this table that the

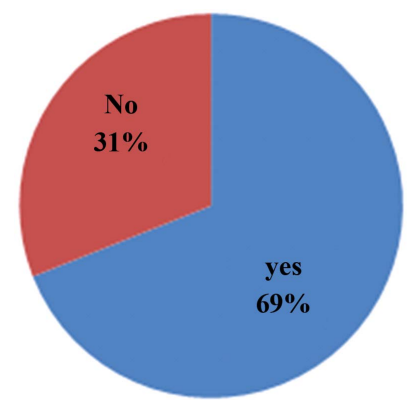

Figure 2. Percentage of the knowledgments the smokers about the deposition of radionuclides in the lung.

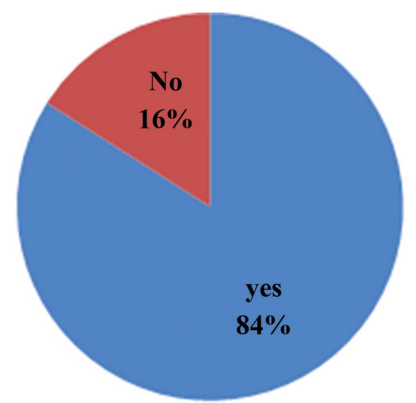

Figure 3. Percentage of smokers who smoke a cigarette to its end. 


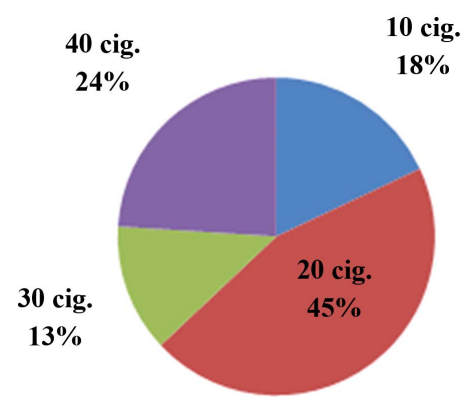

Figure 4. The average number of cigarette which smoking per day.

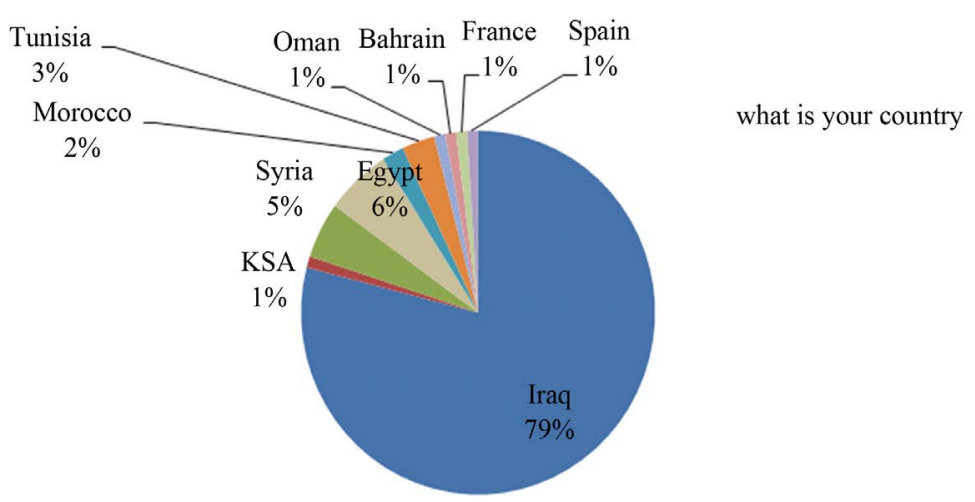

Figure 5. Smokers country from internet survey.

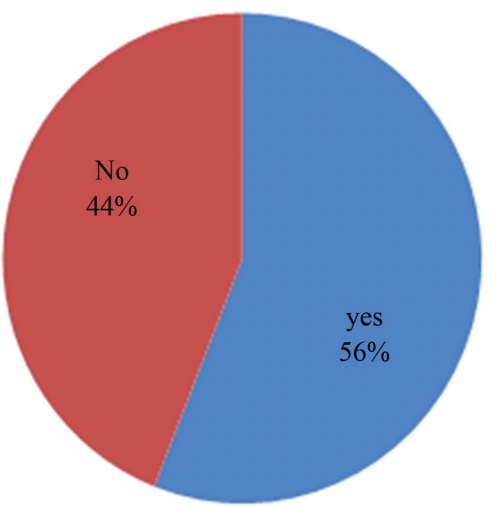

Figure 6. Percentage of the knowledgments of smokers about the deposition of radionuclides in the lung.

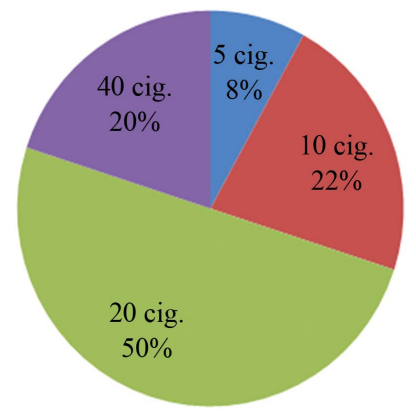

Figure 7. The average number of cigarettes which smoking per day from the internet survey. 
Table 2. Specific activity of radionuclides in tobacco samples.

\begin{tabular}{|c|c|c|c|c|c|}
\hline No. & Sample code & Origin & U-238 (Bq/kg) & Th-232 (Bq/kg) & $\mathrm{K}-40$ (Bq/kg) \\
\hline 1 & $\mathrm{AKH}$ & Armenia & $7.63 \pm 2.76$ & $8.72 \pm 2.95$ & $969.35 \pm 41.91$ \\
\hline 2 & ARD1 & England & $15.67 \pm 3.96$ & $4.95 \pm 2.23$ & $880.17 \pm 43.79$ \\
\hline 3 & ARD2 & England & $3.75 \pm 1.94$ & BLD & BLD \\
\hline 4 & ASP1 & Germany & $16.56 \pm 4.07$ & $5.19 \pm 2.28$ & $840.78 \pm 45.27$ \\
\hline 5 & ASP2 & Germany & $9.30 \pm 3.05$ & $7.13 \pm 2.67$ & $1102.97 \pm 53.01$ \\
\hline 6 & DAV & Germany & $17.39 \pm 4.17$ & $8.05 \pm 2.84$ & $1294.47 \pm 55.25$ \\
\hline 7 & ELE & American & $4.29 \pm 2.07$ & $5.49 \pm 2.34$ & $825.56 \pm 39.40$ \\
\hline 8 & GAU1 & European & $27.03 \pm 5.20$ & $6.83 \pm 2.61$ & $1014.35 \pm 53.61$ \\
\hline 9 & GAU2 & France & $13.36 \pm 3.65$ & $15.80 \pm 3.97$ & $1179.42 \pm 47.37$ \\
\hline 10 & GHA & Yamen & $9.99 \pm 3.16$ & $8.05 \pm 2.84$ & $942.85 \pm 42.68$ \\
\hline 11 & GIT & European & BLD & $1.59 \pm 1.26$ & BLD \\
\hline 12 & GOL & Germany & $12.85 \pm 3.58$ & BLD & BLD \\
\hline 13 & CRA & Turkey & $22.50 \pm 4.74$ & $14.71 \pm 3.84$ & $1029.34 \pm 50.96$ \\
\hline 14 & IRA & Iraqi & $7.01 \pm 2.65$ & $13.01 \pm 3.61$ & $1067.82 \pm 39.41$ \\
\hline 15 & KEN & British & $10.35 \pm 3.22$ & $12.37 \pm 3.52$ & $801.41 \pm 44.59$ \\
\hline 16 & MAC & Brazil & $30.92 \pm 5.56$ & $13.56 \pm 3.68$ & $1567.46 \pm 56.27$ \\
\hline 17 & MAR & Turkey & $19.95 \pm 4.47$ & $1.88 \pm 1.37$ & $924.59 \pm 48.87$ \\
\hline 18 & MEN & Germany & $18.43 \pm 4.29$ & $16.48 \pm 4.06$ & $1326.16 \pm 53.83$ \\
\hline 19 & MIA1 & American & $20.61 \pm 4.54$ & $41.50 \pm 6.44$ & $943.50 \pm 44.68$ \\
\hline 20 & MIA2 & American & $19.71 \pm 4.44$ & $20.06 \pm 4.48$ & $1129.80 \pm 51.84$ \\
\hline 21 & MIK1 & American & $20.56 \pm 4.53$ & $10.70 \pm 3.27$ & $1392.88 \pm 58.97$ \\
\hline 22 & MIK2 & American & $16.01 \pm 4.00$ & $12.78 \pm 3.57$ & $1047.83 \pm 49.34$ \\
\hline 23 & MIN & American & $9.55 \pm 3.09$ & $14.41 \pm 3.80$ & $1080.99 \pm 48.78$ \\
\hline 24 & OSC1 & American & $16.42 \pm 4.05$ & $6.18 \pm 2.49$ & $930.50 \pm 35.58$ \\
\hline 25 & OSC2 & American & $9.97 \pm 3.16$ & $10.13 \pm 3.18$ & $1123.70 \pm 52.97$ \\
\hline 26 & PIN1 & Korea & $16.80 \pm 4.10$ & $11.47 \pm 3.39$ & $912.10 \pm 45.89$ \\
\hline 27 & PIN2 & Korea & $6.84 \pm 2.62$ & $7.24 \pm 2.69$ & $1039.55 \pm 42.30$ \\
\hline 28 & PRE & Bulgaria & BLD & $9.16 \pm 3.03$ & BLD \\
\hline 29 & ROT & Germany & $19.99 \pm 4.47$ & $9.65 \pm 3.11$ & $885.37 \pm 47.06$ \\
\hline 30 & SUM & Iriqi & $16.40 \pm 4.05$ & $15.56 \pm 3.94$ & $1282.20 \pm 51.54$ \\
\hline 31 & WES & Germany & $11.11 \pm 3.33$ & $1.63 \pm 1.28$ & $832.24 \pm 39.15$ \\
\hline \multicolumn{3}{|c|}{ Max } & $30.92 \pm 5.56$ & $41.50 \pm 6.44$ & $1567.46 \pm 58.97$ \\
\hline \multicolumn{3}{|c|}{ Min } & $3.75 \pm 1.94$ & $1.59 \pm 1.26$ & $801.41 \pm 35.5$ \\
\hline \multicolumn{3}{|c|}{ Avearge } & $14.86 \pm 3.76$ & $10.84 \pm 3.13$ & $1050.64 \pm 47.57$ \\
\hline \multicolumn{3}{|c|}{ Worldwide average [17] } & 35 & 30 & 400 \\
\hline
\end{tabular}

${ }^{*}$ Radioactive decay is truly a random process that obeys Poisson distribution. In order to calculate the statistical error for any selected parameter $(n)$, which has a certain result. The standard deviation (statistical error) can be considered as $\sqrt{n}$ (i.e. considered $n$ as a true mean). Therefore, the reported parameter will be $n \pm \sqrt{n} \quad[19]$. 
specific activity concentrations for U-238, have been found to be in the range of $3.75 \pm 1.94 \mathrm{~Bq} / \mathrm{kg}$ in England tobacco sample (ARD2) to $30.92 \pm 5.56 \mathrm{~Bq} / \mathrm{kg}$ in Brazilian tobacco sample (MAC) with an average of $14.86 \pm$ $3.76 \mathrm{~Bq} / \mathrm{kg}$. While for Th-232, they are within the range of $1.59 \pm 1.26 \mathrm{~Bq} / \mathrm{kg}$ in European sample (GIT) to $41.50 \pm 6.44 \mathrm{~Bq} / \mathrm{kg}$ in American sample (MIA1) with an average of $10.84 \pm 3.13 \mathrm{~Bq} / \mathrm{kg}$. The specific activity for $\mathrm{K}-40$ are from $801.41 \pm 35.5 \mathrm{~Bq} / \mathrm{kg}$ in British tobacco (KEN) to $1567.46 \pm 58.97 \mathrm{~Bq} / \mathrm{kg}$ in Brazilian tobacco sample (MAC) with an average value of $1050.64 \pm 47.57 \mathrm{~Bq} / \mathrm{kg}$.

The results show that all the values of Potassium specific activity for tobacco samples are greater than the worldwide average (400) Bq/kg [17]. While the specific activity for all samples are less than the Uranium and thorium worldwide average (35.30 Bq/kg) [18] respectively, except for MIA1 samples which is greater than the worldwide average for thorium. The determination of three isotopes (U-238, Th-232, K-40) is also shown in Figure 8 and Figure 9.

\subsection{Annual Effective Dose}

By using equation (2), we have calculated annual effective dose. Table 3 tabulated the results values which vary from $16.38 \mu \mathrm{Sv} / \mathrm{y}$ to $44.69 \mu \mathrm{Sv} / \mathrm{y}$ with average $24.97 \mu \mathrm{Sv} / \mathrm{y}$.

\subsection{The Annual Gonadal Dose Equivalent (AGDE)}

By using equation (3) we have been calculated the annual gonadal dose equivalent (AGDE) which are calculated and listed in Table 3. The values vary from 0.3 to $0.64(\mathrm{mSv} / \mathrm{y})$ with an average value of 0.42 for tobacco samples.

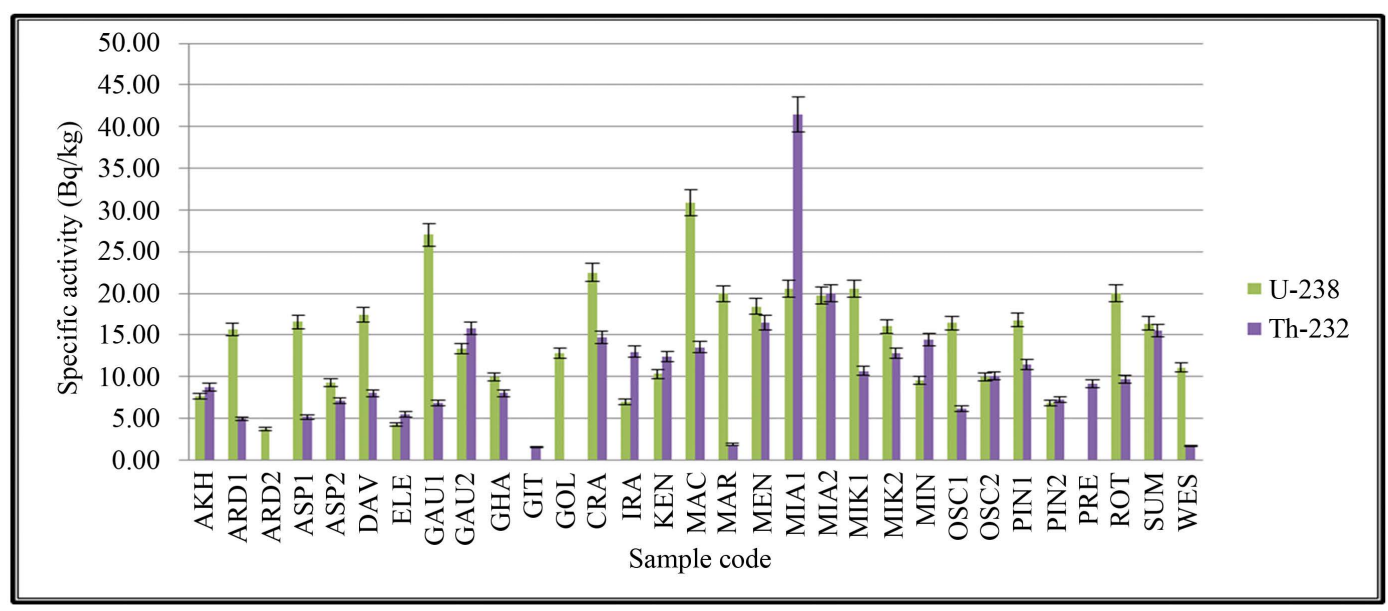

Figure 8. Specific activity of U-238 and Th-232 for each tobacco sample.

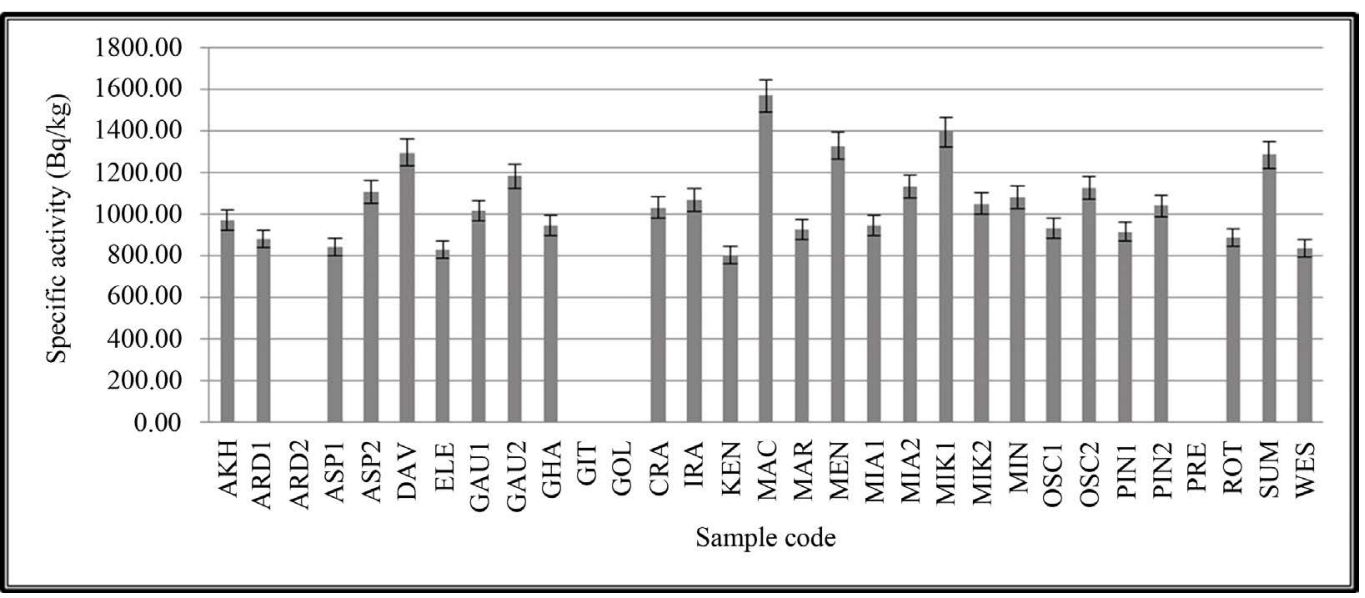

Figure 9. Specific activity of K-40 for each tobacco sample. 
Table 3. Annual effective dose, The Annual Gonadal Dose Equivalent (AGDE), Radium Equivalent, Excess Lifetime Cancer Risk (ELCR) in Tobacco sample.

\begin{tabular}{|c|c|c|c|c|c|c|c|c|}
\hline \multirow{2}{*}{ No } & \multirow{2}{*}{$\begin{array}{l}\text { Sample } \\
\text { code }\end{array}$} & \multicolumn{4}{|c|}{$\begin{array}{c}\text { Annual effective dose of smokers in smoking } 30 \\
\text { cigarettes per day }(\mu \mathrm{sv} / \mathrm{y})\end{array}$} & \multirow{2}{*}{$\begin{array}{l}\text { AGDE } \\
(\mathrm{msv} / \mathrm{y})\end{array}$} & \multirow{2}{*}{$\begin{array}{c}R a_{e q} \\
\mathbf{B q} / \mathbf{k g}\end{array}$} & \multirow{2}{*}{$\begin{array}{l}\text { (ELCR) person per } \\
\text { million person per year }\end{array}$} \\
\hline & & U-238 & Th-232 & K-40 & total & & & \\
\hline 1 & AKH & 0.33 & 2.02 & 19.60 & 21.95 & 0.36 & 27.57 & 76.83 \\
\hline 2 & ARD1 & 0.63 & 0.91 & 17.79 & 19.33 & 0.35 & 29.53 & 67.69 \\
\hline 3 & ARD2 & 0.15 & BLD & BLD & 0.15 & BLD & BLD & 0.54 \\
\hline 4 & ASP1 & 0.82 & 2.24 & 17.00 & 20.06 & 0.34 & 30.46 & 70.22 \\
\hline 5 & ASP2 & 0.66 & 1.58 & 22.30 & 24.54 & 0.40 & 27.98 & 85.88 \\
\hline 6 & DAV & 1.11 & 0.99 & 26.17 & 28.27 & 0.49 & 38.87 & 98.93 \\
\hline 7 & ELE & 0.29 & 1.22 & 16.69 & 18.2 & 0.30 & 18.50 & 63.70 \\
\hline 8 & GAU1 & 1.80 & 1.87 & 20.51 & 24.18 & 0.43 & 44.62 & 84.62 \\
\hline 9 & GAU2 & 0.67 & 3.97 & 23.84 & 28.48 & 0.48 & 45.03 & 99.69 \\
\hline 10 & GHA & 0.51 & 3.53 & 19.06 & 23.1 & 0.36 & 28.76 & 80.86 \\
\hline 11 & GIT & BLD & 0.38 & BLD & 0.38 & BLD & BLD & 1.33 \\
\hline 12 & GOL & 0.83 & BLD & BLD & 0.83 & BLD & BLD & 2.92 \\
\hline 13 & CRA & 1.06 & 3.80 & 20.81 & 25.67 & 0.45 & 51.46 & 89.84 \\
\hline 14 & IRA & 0.41 & 3.74 & 21.59 & 25.74 & 0.41 & 33.83 & 90.10 \\
\hline 15 & KEN & 0.57 & 2.75 & 16.20 & 19.52 & 0.34 & 34.21 & 68.33 \\
\hline 16 & MAC & 1.65 & 3.72 & 31.69 & 37.06 & 0.64 & 62.37 & 129.70 \\
\hline 17 & MAR & 1.12 & 0.03 & 18.69 & 19.84 & 0.36 & 29.75 & 69.46 \\
\hline 18 & MEN & 0.88 & 3.88 & 26.81 & 31.57 & 0.54 & 52.21 & 110.50 \\
\hline 19 & MIA1 & 1.06 & 11.2 & 19.07 & 31.33 & 0.53 & 87.21 & 109.86 \\
\hline 20 & MIA2 & 1.02 & 5.42 & 22.84 & 29.28 & 0.50 & 57.09 & 102.46 \\
\hline 21 & MIK1 & 1.17 & 2.75 & 28.16 & 32.08 & 0.55 & 46.59 & 112.29 \\
\hline 22 & MIK2 & 0.96 & 4.21 & 21.18 & 26.35 & 0.43 & 42.35 & 92.25 \\
\hline 23 & MIN & 0.52 & 3.91 & 21.85 & 26.28 & 0.43 & 38.48 & 92.00 \\
\hline 24 & OSC1 & 1.02 & 1.28 & 18.81 & 21.11 & 0.37 & 32.42 & 73.89 \\
\hline 25 & OsC2 & 0.53 & 3.34 & 22.72 & 26.59 & 0.43 & 33.11 & 93.06 \\
\hline 26 & PIN1 & 0.96 & 3.17 & 18.44 & 22.57 & 0.39 & 40.22 & 79.01 \\
\hline 27 & PIN2 & 0.39 & 1.93 & 21.02 & 23.34 & 0.38 & 25.20 & 81.68 \\
\hline 28 & PRE & BLD & 3.00 & BLD & 3 & BLD & BLD & 10.48 \\
\hline 29 & ROT & 1.38 & 2.62 & 17.90 & 21.9 & 0.38 & 40.61 & 76.65 \\
\hline 30 & SUM & 0.92 & 4.03 & 25.92 & 30.87 & 0.52 & 48.52 & 108.03 \\
\hline \multirow[t]{4}{*}{31} & WES & 0.58 & 0.52 & 16.82 & 17.92 & 0.30 & 19.85 & 62.75 \\
\hline & Iax & 1.80 & 11.2 & 31.69 & 44.69 & 0.64 & 87.21 & 129.70 \\
\hline & Iin & 0.15 & 0.03 & 16.20 & 16.38 & 0.30 & 18.50 & 0.54 \\
\hline & earge & 0.83 & 2.90 & 21.24 & 24.97 & 0.42 & 39.51 & 76.95 \\
\hline
\end{tabular}




\subsection{Radium Equivalent Activity}

The Radium equivalent activities $\left(R a_{e q}\right)$ are calculated and listed in Table 3. $R a_{e q}$ values vary from 18.50 to 87.21.4 Bq/ kg with an average value of $39.51 \mathrm{~Bq} / \mathrm{kg}$ for tobacco samples. It can be seen that the $R a_{e q}$ values are lower than the global recommended maximum value $370 \mathrm{~Bq} / \mathrm{kg}$ [17].

\subsection{Excess Lifetime Cancer Risk (ELCR)}

Excess lifetime cancer risk (cancer risk per million people per year) ranges from 0.54 in (ARD2) sample to 129.70 in (MAC) sample with an average value of 76.95. see Figure 10. Figure 11 shows the relationship between cancer risk per million smoker per year and annual effective dose for each sample This is an indication that there is a linear relationship between the cancers and the annual effective dose rates of cancer increases with dose.

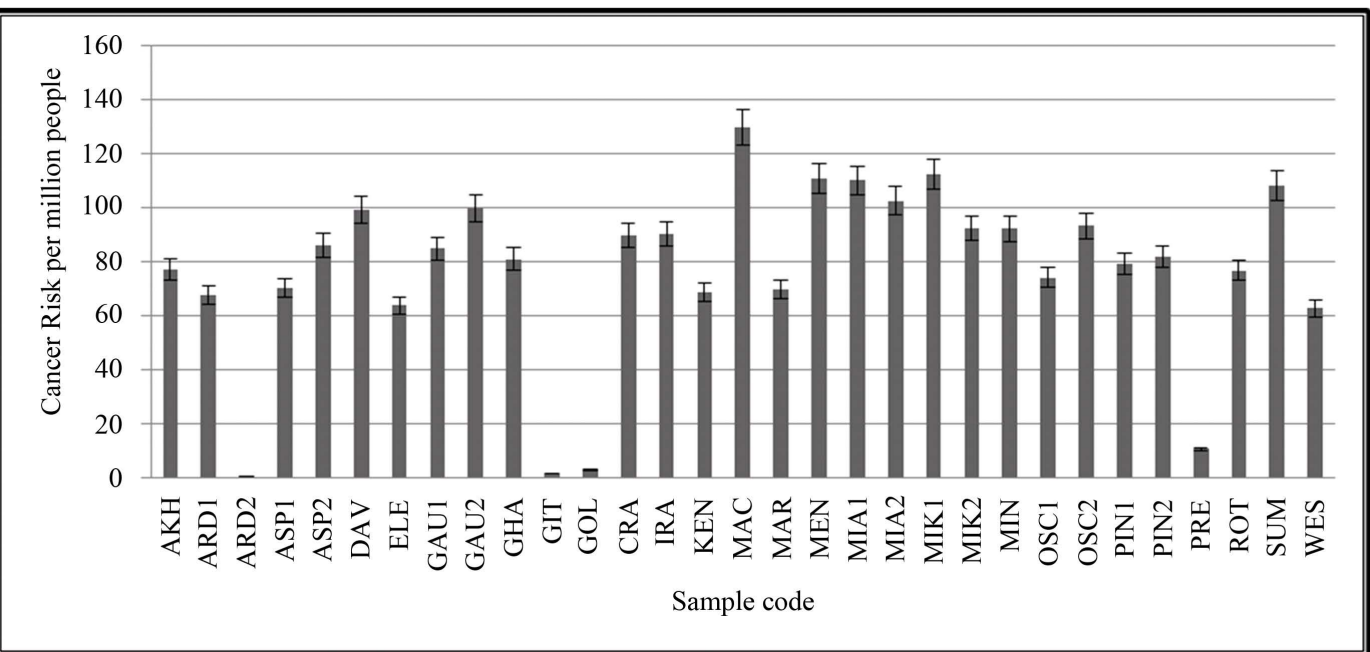

Figure 10. Cancer Risk per million smoker per year for each tobacco sample.

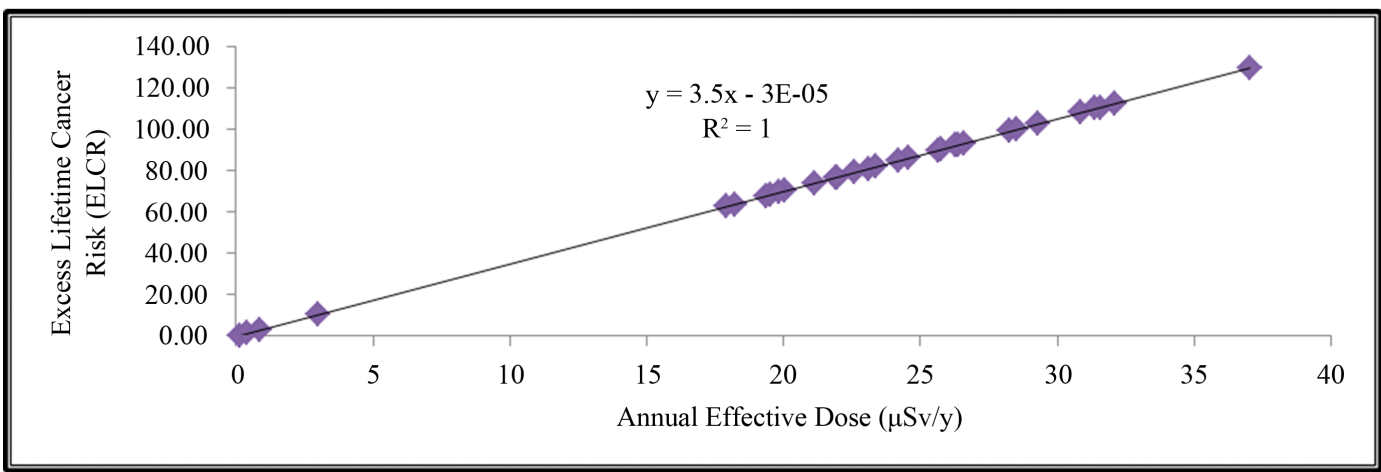

Figure 11. Relationship between excess lifetime Cancer Risk (ELCR) and annual effective dose for each tobacco sample.

\section{Conclusions}

1) HPGe results indicate that the maximum value of U-238 series and K-40 in cigarettes, tobacco sample (MAC) which was made in Brazilian, gives a large dose to the lungs which increase the likelihood of lung cancer cases per million smokers per year. The reason may be in the soil containing high radioactivity or the use of fertilizer containing high concentrations of uranium. It will move into the plant by the roots, and there is a common rich fertilizer in Potassium, Nitrogen, and Phosphorus (called NPK) which are frequently used in the cultivation of tobacco plant, leading to transmission of Potassium-40 isotope to the plant through the roots also. 
2) Cigarette smoking is the main cause of lung cancer. In fact, cigarettes are the cause of the first lung cancer because they contain radioactive elements including radon, which can be inhaled and deposited in the lung and radiate a long time causing the cancers.

3) Tobacco leaves have sticky hairs associated with structures called trichomes. Therefore, small particles from the atmosphere might be collected on these hairs and are not easily removed. In this manner, the longer lived Radon daughters become concentrated in the tobacco leaves.

\section{Acknowledgements}

We offer thanks and appreciation to Dr. Mahmoud Salem Karim from the department of physics in the college of education Al-Mustansiriyah University in cooperation to work in the high-purity germanium system. We also thank Dr. Nada Fadel Tawfiq and Dr. Nada Farhan Kadhim for helping us to provide a standard source for system calibrations, and also for Prof. Laith Ahmed Najam for helping us in reviewing the paper and publishing it.

\section{References}

[1] Abu-Jarad, F. (1997) Indoor Cigarette Smoking Uranium Contents and Carrier of Indoor Radon Products. Radiation Measurements, 28, 579-584. http://dx.doi.org/10.1016/S1350-4487(97)00143-1

[2] Martell, E.A. (1974) Radioactivity of Tobacco Trichomes and Insoluble Cigarette Smoke Particles. Nature, 249, 215217. http://dx.doi.org/10.1038/249215a0

[3] Pooja, C. and Chauhan, R.P. (2014) Measurement of Fertilizers Induced Radioactivity in Tobacco Plants and Elemental Analysis Using ICAP-AES. Radiation Measurements, 63, 6-11. http://dx.doi.org/10.1016/j.radmeas.2014.02.006

[4] Ashraf, E.M., Khater, N.S., El-Aziz, A., Al-Sewaidan, H.A. and Chaouachi, K. (2008) Radiological Hazards of Narghile (Hookah, Shisha, Goza) Smoking: Activity Concentrations and Dose Assessment. Journal of Environmental Radioactivity, 99, 1808-1814. http://dx.doi.org/10.1016/j.jenvrad.2008.07.005

[5] Papastefanou, C. (2001) Radioactivity in Tobacco Leaves. Journal of Environmental Radioactivity, 53, 67-73. http://dx.doi.org/10.1016/S0265-931X(00)00109-0

[6] Mussalo, H. and Jaakkola, T. (2012) Plutonium-239, 240 and Po-210 Contents of Tobacco and Cigarette Smoke. Health Physics, 49, 296-301.

[7] Jose, A., Jorge, J., Cleomacio, M., Sueldo, V. and Romilton dos, S. (2005) Analysis of the K-40 Levels in Soil Using Gamma Spectrometry. Brazilian Archives of Biology and Technology Journal, 48, 221-228. http://dx.doi.org/10.1590/S1516-89132005000700033

[8] Khater, A.E. (2004) Polonium-210 Budget in Cigarettes. Journal of Environmental Radioactivity, 71, 33-41. http://dx.doi.org/10.1016/S0265-931X(03)00118-8

[9] Papastefanou, C. (2009) Radioactivity of Tobacco Leaves and Radiation Dose Induced from Smoking. Aristotle University of Thessaloniki International Journal of Environmental Research and Public Health, 6, 558-567. http://dx.doi.org/10.3390/ijerph6020558

[10] (NRPB) National Radiological Protection Board (1991) Committed Equivalent Organ Doses and Committed Effective Doses from Intakes of Radionuclides. NRPB Report M. Chilton, Didcot, UK, 288.

[11] Bousher, H., Jensen, A., Jackson, P.H., Lambers, D. and Zeevaert, B., European Commission (1999) Investigation of a Possible Basis for a Common Approach with Regard to the Restoration of Areas Affected by Lasting Radiation Exposure as a Result of Past or Old Practice or Work Activity. CARE Final Report, Vandenhove, European Commission DG XI Environment, Nuclear Safety and Civil Protection, under Contract 96-ET-006, Brussels.

[12] (ICRP) International Commission on Radiological Protection (1996) Age-Dependent Doses to Members of the Public from Intake of Radionuclides. Part 5: Compilation of Ingestion and Inhalation Dose Coefficients. ICRP Publication 72, Pergamon Press, Oxford.

[13] Najam, L.A., Tawfiq, N.F. and Younis, S.A. (2015) A Comparative Study of the Results of Natural Radioactivity and the Associated Radiation Hazards of $\mathrm{Na}(\mathrm{Tl})$ and HPGe Detectors. International Journal of Recent Research and Review, 8, 1-7.

[14] Avwiri, G.O., Egieya, J.M. and Ononugbo, C.P. (2013) Radiometric Assay of Hazard Indices and Excess Lifetime Cancer Risk Due to Natural Radioactivity in Soil Profile in Ogba/Egbema/Ndoni Local Government Area of Rivers State, Nigeria. Academic Research International, 4.

[15] Mujahid, S.A., Rahim, A., Hussain, S. and Farooq, M. (2008) Measurements of Natural Radioactivity and Radon Exhalation Rates from Different Brands of Cement Used in Pakistan. Radiation Protection Dosimeter Journal, 130, 206212. http://dx.doi.org/10.1093/rpd/ncm497 
[16] Taskin, H., Karavus, M., Ay, P., Touzogh, A., Hindiroglu, S. and Karaham, G. (2009) Radionuclide Concentration in Soil and Lifetime Cancer Risk Due to the Gamma Radioactivity in Kirklareli Turkey. Journal of Environmental Radioactivity, 100, 49-53. http://dx.doi.org/10.1016/j.jenvrad.2008.10.012

[17] (UNSCEAR) (1989) United Nations Scientific Committee on the Effects of Atomic Radiation, Report to the General Assembly: Sources and Effects of Ionizing Radiation, New York.

[18] (UNSCEAR) (2000) United Nations Scientific Committee on the Effect of Atomic Radiation, Report to the General Assembly. Annex B: Exposures from Natural Radiation Sources, New York.

[19] Al-Saif, A.S. (2009) Radioecological Aspects of Hail Region: Behavior of Some Radionuclides in Soil. M.Sc. Thesis, College of Science, King Saud University, KSA. 